\title{
Efeitos da Substituição do Milho pelo Resíduo de Panificação sobre as Características de Carcaça de Novilhos da Raça Holandesa ${ }^{1}$
}

\author{
Roberta Passini ${ }^{2}$, Aleksandrs Spers ${ }^{3}$, Carlos de Souza Lucci ${ }^{4}$
}

\begin{abstract}
RESUMO - Foram estudados os efeitos da adição de resíduo de panificação (RP) em substituição ao milho na dieta de novilhos da raça Holandesa sobre rendimento de carcaça e qualidade da carne. Foram aplicados quatro tratamentos, respectivamente, 0 , 10, 20 e $30 \%$ de RP em substituição ao milho, na mistura de concentrados. Os animais foram alimentados com ração completa peletizada, contendo $30 \%$ de feno de Coast-cross (Cynodon dactylon L.) como volumoso. O delineamento experimental foi em blocos casualizados, com quatro tratamentos e cinco repetições, totalizando 20 animais. O experimento teve início quando os animais atingiram $90 \mathrm{~kg}$ de peso vivo e durou 120 dias. Ao término do experimento os animais foram abatidos, sendo avaliados rendimento de carcaça e porcentagem de cortes comerciais, composição e qualidade da carne. A qualidade da carne foi avaliada por intermédio da coloração, maciez e composição química (umidade, gordura, proteína e minerais). Os resultados não mostraram diferenças entre os tratamentos para os parâmetros estudados. Portanto, o resíduo de panificação pode ser considerado uma fonte alternativa viável para a alimentação dos novilhos, em comparação com o milho.
\end{abstract}

Palavras-chave: carcaça, novilhos, qualidade de carne, resíduo de panificação

\section{Effects of Corn Replacement by Bakery Waste on Carcass Characteristics and Meat Quality of Holstein Steers}

\begin{abstract}
The effects of the addition of bakery waste (BW) replacing corn in the diet of Holstein steers was studied on carcass dressing and meat quality. Four treatments were applied, respectively, $0 \%, 10 \%, 20 \%$ and $30 \%$ of bakery waste replacing corn in the concentrated mixture. The animals were fed with complete pelleted mixtures, with $30 \%$ of Coast-cross hay (Cynodon dactylon L.) as roughage. A randomized block design with four treatments and five repetitions, total of 20 animals, was used. The experiment began when the calves reached $90 \mathrm{~kg}$ of live weight and lasted for 120 days. At the end of experiment, the animals were slaughtered and carcass dressing, commercial cuts and meat composition and quality were evaluated. The meat quality was evaluated by color, tenderness and chemistry composition (moisture, fat, protein and minerals). The results showed no differences among treatments concerning parameters studied $(\mathrm{P}>0,05)$. Therefore, bakery waste can be considered an alternative source for feeding growing steers, when compared with corn.
\end{abstract}

Key Words: bakery waste, carcass, steers, meat quality

\section{Introdução}

Com o crescimento da exploração leiteira em áreas anteriormente ocupadas pela pecuária de corte, surgiu um grande número de animais mestiços e leiteiros, os quais são geralmente engordados a pasto e abatidos, tornando-se seguimentos importantes da indústria de carne (MATTOS et al., 1978). Segundo VELLOSO et al. (1975) bezerros machos de raças leiteiras apresentam excelente desempenho, quando mantidos em sistema de confinamento.

Segundo BEAUCHEMIN et al. (1990), a produção moderna de vitelos provê uma alternativa para o uso de bezerros machos de raças leiteiras, contudo, o lucro deste tipo de criação é pequeno em virtude do alto custo de alimentação, devido aos preços dos substitutos de leite (LUCCI, 1989). Dessa forma, a inclusão de grãos ou subprodutos industriais nas dietas destes animais torna-se uma alternativa econômica.

Os subprodutos são classificados de acordo com suas composições químicas, de forma que aqueles com altas concentrações de carboidratos digestíveis, como por exemplo o resíduo de panificação (RP), são referidos como alimentos energéticos (AROSEMENA et al., 1995). Segundo DALE (1986), se for atribuído um valor de 100 para a energia metabolizável verdadeira do milho, o conteúdo relativo da energia para o RP seria de 110,5 com base na matéria seca.

Análises relatadas por BATH et al. (1993/94) classificam o RP como um alimento altamente

\footnotetext{
${ }_{1}^{1}$ Parte da Dissertação de Mestrado do primeiro autor apresentada à FMVZ/USP, Campus de Pirassununga, SP.

${ }^{2}$ Médica Veterinária, MSc. Nutrição Animal, Dra. Zootecnia. Rua Major Braga, 793. CEP 13.860-000. Aguaí, SP. E.mail: rpassini@bol.com.br

3 Professor Titular do Departamento de Nutrição e Produção Animal, FMVZ/USP.

${ }^{4}$ Professor Titular, UNIMES - Universidade Metropolitana de Santos.
} 
energético e relativamente protéico. MILLER et al. (s.d.) referiram-se ao RP como um subproduto similar ao milho, com base no seu teor protéico e composição de aminoácidos, reportando um valor para energia metabolizável de $3666 \mathrm{kcal} / \mathrm{kg}$, devido ao seu elevado teor de gordura. MORRISON (1966) reportou o valor destes resíduos em $75 \%$ do valor do milho ou outros grãos, diferindo pelo baixo conteúdo de fibras.

Consideráveis quantidades de resíduos de panificação estão disponíveis para serem utilizadas na alimentação animal, incluindo-se nestas as sobras de bolos, restos de pães, biscoitos doces e salgados, produtos não comercializados ou que ultrapassaram o prazo de validade, além das perdas por quebras, excesso ou falta de cozimento durante o processamento (WING, 1965; HARMS et al., 1966; KORNEGAY, 1974; ADAMS, 1990).

Contudo, poucos trabalhos avaliaram o uso do RP como ingrediente das rações para ruminantes. Estudos foram desenvolvidos com vacas leiteiras (WING, 1965; ADAMS, 1990), novilhos (MILTON e BRANDT, 1993), ovinos (CHAMPE e CHURCH, 1980) e búfalos (SPERS, 1996).

ADAMS (1990) relata que o RP pode ser usado até um nível máximo de $20 \%$ da matéria seca do concentrado ou $10 \%$ da matéria seca da ração total para vacas leiteiras. Segundo HARRIS e STAPLER (1993), o RP pode ser usado numa proporção de 20 a $25 \%$ do concentrado destinado à alimentação de ruminantes.

MILTON e BRANDT (1993) avaliaram o desempenho de novilhos de corte em terminação alimentados com rações contendo RP substituindo o milho em 15 e $30 \%$ da matéria seca dietética, mantendo-se todas as rações isonitrogenadas. Neste estudo, a ingestão de matéria seca foi reduzida em $6,5 \%$ pela inclusão de $30 \%$ de RP, contudo, nenhuma diferença sobre ganho de peso ou eficiência alimentar foi observada entre os tratamentos.

SPERS (1996), trabalhando com búfalos em crescimento, substituiu o milho por RP nas proporções de 33, 66 e $100 \%$, encontrando efeito positivo sobre o ganho de peso diário até a proporção de $33 \%$ de RP na dieta $(\mathrm{P}<0,01)$, entretanto, a conversão alimentar piorou com as inclusões de RP nos níveis estudados.

Existem poucos trabalhos, nas literaturas nacional e internacional, avaliando a adição de RP nas dietas de bovinos sobre as características de carcaça.

MILTON e BRANDT (1993) avaliaram as características de carcaça de novilhos de corte em terminação. A dieta controle foi composta de $80 \%$ de rolão de milho, $10 \%$ de feno de alfafa picado e $10 \%$ de suplemento e melaço. Em outras duas dietas, o RP substituiu o milho em 15 e $30 \%$ da matéria seca dietética, mantendo-se todas as rações isonitrogenadas. Foi observado aumento linear nas porcentagens de gordura pélvica, renal e cardíaca $(\mathrm{P}<0,05)$ e aumento da espessura de gordura na $12^{\mathrm{a}}$ costela $(\mathrm{P}<0,10)$, à medida que se adicionou RP nas dietas, contudo, o peso da carcaça quente, o rendimento de carcaça e o grau de marmorização não foram afetados pelas adições de RP nas proporções estudadas.

Existem diferenças de ordem racial sobre as características de carcaça e composição. BOND et al. (1972) compararam as raças Holandesa, Jersey, Shorthorn leiteiro, Angus e Hereford sob vários aspectos, concluindo que os novilhos da raça Holandesa ganharam peso mais rapidamente, com conversão alimentar igual aos da raça Shorthorn, porém, melhor que as demais raças. Esta raça apresentou ainda a maior área de olho de lombo $\left(70 \mathrm{~cm}^{2}\right)$, enquanto que os da raça Jersey obtiveram a menor $\left(56 \mathrm{~cm}^{2}\right)$, ficando as demais raças com valores intermediários. Contudo, os animais da raça Holandesa foram menos eficientes em deposição de gordura que os de raças de corte, refletindo diferenças genéticas quanto a esta habilidade, sendo este o único aspecto desfavorável para os animais de raças leiteiras. Os animais da raça Holandesa apresentam carcaças menos gordurosas, com menor índice de marmorização e com maior percentagem de músculos que os animais de raças zebuínas (COLE et al., 1964).

Estudos envolvendo novilhos das raças Japonesa Preta, Shorthorn Japonesa, Holandesa e mestiços destas raças, avaliando a deposição de lipídeos intramuscular no músculo Longissimus dorsi, concluíram que o grau de deposição de gordura é altamente dependente do potencial genético dos animais, podendo estar relacionada mais estreitamente com a idade do que com a velocidade de crescimento e engorda (ZEMBAYASHI, 1994). Constatou-se, ainda, que o aumento na porcentagem de gordura da carcaça ou na idade ao abate de bovinos é, geralmente, acompanhado de decréscimo na eficiência de produção de carne.

No que se refere ao rendimento de carcaça e qualidade da carne, BOND et al. (1972) relataram que, novilhos da raça Holandesa apresentam maior porcentagem de carne magra quando comparados 
com animais das raças Jersey, Shorthorn, Angus e Hereford, entretanto, com porcentagens superiores de ossos, proporcionalmente ao peso da carcaça. Nos testes de maciez (Warner-Bratzler) e sabor não foram encontradas diferenças significativas entre as raças estudadas.

BEAUCHEMIN et al. (1990), trabalhando com vitelos da raça Holandesa alimentados com dietas contendo substituto do leite, cevada ou milho, relataram grande potencial para ganho de peso nos animais alimentados com dietas contendo grãos $(1,03 \mathrm{~kg} / \mathrm{dia}$ em média), contudo, a coloração da carne tornou-se mais escura, fator que poderia determinar a extensão na qual os grãos podem ser incluídos nas rações para esta categoria animal.

O objetivo do presente trabalho foi estudar os efeitos da substituição parcial do milho pelo resíduo de panificação (RP) proveniente da fabricação de biscoitos, na dieta de novilhos da raça Holandesa, sobre o rendimento de carcaça, composição e qualidade da carne.

\section{Material e Métodos}

O experimento foi desenvolvido na Faculdade de Medicina Veterinária e Zootecnia-USP, Campus de Pirassununga. A região possui clima subtropical, com verão chuvoso e inverno seco, do tipo Cwa de Köppen (OLIVEIRA e PRADO, 1984), com temperatura média anual de $22^{\circ} \mathrm{C}$. A instalação experimental utilizada foi um galpão coberto, com bebedouros comunitários de alvenaria e cochos individuais para alimentação, confeccionados em madeira.

$\mathrm{O}$ resíduo de panificação (RP) utilizado neste estudo constituiu-se de sobras da fabricação de biscoitos provenientes de algumas fábricas da região de Marília-SP. A composição química do resíduo de panificação e do milho usado na formulação das dietas experimentais está mostrada na Tabela 1 .
As dietas experimentais foram compostas de milho moído (fubá), farelo de trigo, farelo de soja, RP e feno de coastcross (Cynodon dactylon L.), usado como único volumoso, picado em peneira de $4 \mathrm{~mm}$. Um suplemento mineral fez parte de $1 \%$ da mistura de concentrados. Os concentrados e o volumoso foram misturados e peletizados na forma de ração completa.

No período pré-experimental, os animais receberam dieta balanceada segundo as recomendações do NATIONAL RESEARCH COUNCIL - NRC (1989) de forma a permitir um ganho de peso não inferior a $1 \mathrm{~kg} / \mathrm{dia}$, sendo fornecido feno de Coast-cross integral como volumoso, na proporção de $30 \%$ da ração total. Esse período compreendeu 30 dias, destinados à adaptação dos animais ao manejo e instalações experimentais.

No período experimental, a alimentação foi fornecida duas vezes ao dia, pela manhã ( $7 \mathrm{~h} 30$ às $8 \mathrm{~h} 30$ ) e à tarde (13h30 às 14h30), ficando a água disponível ad libitum. A ingestão de alimentos foi monitorada diariamente, através da pesagem do alimento oferecido e das sobras, ajustando o consumo à vontade para o dia seguinte. Consta da Tabela 2 a proporção dos ingredientes nas rações experimentais, com base na matéria seca. Na Tabela 3 está demonstrada a composição química das diferentes dietas experimentais, com base na matéria seca.

Os animais foram provenientes de uma única propriedade, totalizando vinte bezerros machos da raça Holandesa, variedade preta e branca, puros por cruzamento, todos saudáveis e que receberam quantidades adequadas de colostro materno.

O experimento teve início com aproximadamente 60 dias após o desaleitamento, quando os animais apresentavam em média $90 \mathrm{~kg}$ de peso vivo, e se estendeu por 120 dias. Foram realizadas duas pesagens iniciais, com jejum prévio alimentar e hídrico de 12 horas, no primeiro e segundo dias experimentais,

Tabela 1 - Composição química do resíduo de panificação e do milho das dietas experimentais, com base na matéria seca Table 1 - Chemical composition of the bakery waste and corn of the experimental diets, on dry matter basis

\begin{tabular}{|c|c|c|c|c|c|c|c|}
\hline Alimentos & MS & PB & FB & $\mathrm{EE}$ & Cinzas & $\mathrm{Ca}$ & $\mathrm{P}$ \\
\hline Feeds & $D M$ & $C P$ & $C F$ & $E E$ & Ash & $\mathrm{Ca}$ & $P$ \\
\hline $\begin{array}{l}\text { Resíduo de panificação } \\
\text { Bakery waste }\end{array}$ & 93,14 & 9,39 & 0,04 & 17,11 & 1,91 & 0,075 & 0,17 \\
\hline $\begin{array}{l}\text { Milho, moído } \\
\text { Corn, ground }\end{array}$ & 88,93 & 11,69 & 2,69 & 4,97 & 1,58 & 0,11 & 0,26 \\
\hline
\end{tabular}

Matéria seca (MS), proteína bruta (PB), fibra bruta (FB), extrato etéreo (EE), cinzas, cálcio (Ca) e fósforo $(P)$.

Dry matter (DM), crude protein (CP), crude fiber (CF), ether extract (EE), ash, calcium (Ca) phosphorus (P).

Rev. bras. zootec., 30(5):1550-1557, 2001 
Tabela 2 - Composição percentual das dietas, com base na matéria seca

Table 2 - Percentual diets composition, on dry matter basis

\begin{tabular}{|c|c|c|c|c|}
\hline \multirow[b]{2}{*}{$\begin{array}{l}\text { Ingredientes } \\
\text { Ingredients }\end{array}$} & \multicolumn{4}{|c|}{$\begin{array}{c}\text { Tratamentos } \\
\text { Treatments }\end{array}$} \\
\hline & $\begin{array}{l}\mathrm{RP} 0 \\
B W 0\end{array}$ & $\begin{array}{l}\mathrm{RP} 10 \\
B W 10\end{array}$ & $\begin{array}{l}\mathrm{RP} 20 \\
B W 20\end{array}$ & $\begin{array}{l}\mathrm{RP} 30 \\
B W 30\end{array}$ \\
\hline $\begin{array}{l}\text { Resíduo de } \\
\text { panificação } \\
\text { Bakery waste }\end{array}$ & 0 & 7,26 & 14,48 & 21,63 \\
\hline $\begin{array}{l}\text { Milho, moído } \\
\text { Corn, ground }\end{array}$ & 45,69 & 38,45 & 31,19 & 24,04 \\
\hline $\begin{array}{l}\text { Farelo de soja } 46 \% \\
\text { Soybean meal }(46 \%)\end{array}$ & 16,18 & 16,27 & 16,27 & 16,43 \\
\hline $\begin{array}{l}\text { Farelo de trigo } \\
\text { Wheat meal }\end{array}$ & 6,99 & 6,97 & 6,97 & 6,95 \\
\hline $\begin{array}{l}\text { Suplemento mineral }{ }^{1} \\
\text { Mineral supplement }^{1}\end{array}$ & 0,78 & 0,78 & 0,78 & 0,78 \\
\hline $\begin{array}{l}\text { Feno de coastcross } \\
\text { Coastcross hay }\end{array}$ & 30,36 & 30,27 & 30,31 & 30,17 \\
\hline
\end{tabular}

RP: Resíduo de panificação.

1 Suplemento mineral (níveis de garantia por kg do produto) (Mineral supplement [level of guarantee per $\mathrm{kg}$ of the product]): $\mathrm{P} 80 \mathrm{~g}, \mathrm{Ca} 140 \mathrm{~g}, \mathrm{Na}$ 112 g, Mg 25 g, Mn 1260 mg, Fe 1300 mg, Zn 2520 mg, Cu 1500 mg, Co $200 \mathrm{mg}$, I $195 \mathrm{mg}$, Se $20 \mathrm{mg}$, Fluor máximo (maximum fluor) $800 \mathrm{mg}$, veículo q.s.p. $1000 \mathrm{~g}$.

BW: Bakery waste.
Tabela 3 - Composição química das dietas experimentais, com base na matéria seca

Table 3 - Chemical composition of the experimental diets, on dry matter basis

\begin{tabular}{|c|c|c|c|c|}
\hline \multirow[b]{2}{*}{$\begin{array}{l}\text { Composição química } \\
\text { Chemical composition }\end{array}$} & \multicolumn{4}{|c|}{$\begin{array}{c}\text { Tratamentos } \\
\text { Treatments }\end{array}$} \\
\hline & $\begin{array}{l}\mathrm{RP} 0 \\
B W 0\end{array}$ & $\begin{array}{l}\mathrm{RP} 10 \\
B W 10\end{array}$ & $\begin{array}{l}\mathrm{RP} 20 \\
B W 20\end{array}$ & $\begin{array}{l}\mathrm{RP} 30 \\
B W 30\end{array}$ \\
\hline $\begin{array}{l}\text { Matéria seca } \\
\text { Dry matter }\end{array}$ & 89,11 & 89,41 & 89,54 & 89,31 \\
\hline $\begin{array}{l}\text { Proteína bruta } \\
\text { Crude protein }\end{array}$ & 16,39 & 16,41 & 16,02 & 16,30 \\
\hline $\begin{array}{l}\text { Fibra bruta } \\
\text { Crude fiber }\end{array}$ & 10,71 & 10,32 & 10,56 & 10,85 \\
\hline $\begin{array}{l}\text { Fibra em detergente } \\
\text { neutro } \\
\text { Neutral detergent fiber }\end{array}$ & 29,34 & 27,41 & 27,44 & 28,00 \\
\hline $\begin{array}{l}\text { Fibra em detergente } \\
\text { ácido }\end{array}$ & 14,70 & 14,27 & 14,10 & 15,02 \\
\hline $\begin{array}{l}\text { Acid detergent fiber } \\
\text { Extrato etéreo } \\
\text { Ether extract }\end{array}$ & 2,37 & 3,14 & 3,60 & 4,61 \\
\hline $\begin{array}{l}\text { Matéria mineral } \\
\text { Minerals }\end{array}$ & 4,23 & 3,99 & 4,21 & 3,80 \\
\hline $\begin{array}{l}\text { Cálcio } \\
\text { Calcium }\end{array}$ & 0,43 & 0,37 & 0,43 & 0,36 \\
\hline $\begin{array}{l}\text { Fósforo } \\
\text { Phosphorus }\end{array}$ & 0,40 & 0,37 & 0,38 & 0,33 \\
\hline
\end{tabular}

RP: Resíduo de panificação.

$B W$ : Bakery waste.

douro Escola da Universidade de São Paulo, sempre em jejum hídrico e alimentar prévio de 12 horas.

Por ocasião do abate, foram submetidas à pesagem as meias-carcaças quentes (direita e esquerda), sendo mensurados o comprimento e a profundidade das mesmas. O comprimento da carcaça refere-se à medida do púbis ao bordo anterior da primeira costela, sendo a profundidade mensurada na altura da $5^{\text {a }}$ costela, medindo a distância das referidas costelas (bordo superior ao bordo inferior), alcançando a região esternal (peito) e da coluna vertebral. Em seguida, as carcaças foram resfriadas em câmara fria a temperatura de $4^{\circ} \mathrm{C}$ por 24 horas. Depois de resfriadas, as meias carcaças direitas foram desossadas, sendo separados e submetidos à pesagem os cortes comerciais do dianteiro (paleta, acém, peito, pescoço e músculo), traseiro especial (filé mignon, alcatra completa, contra filé, fraldinha, coxão mole, coxão duro, patinho, lagarto, músculo e capa de filé) e ponta de agulha (ponta e costela), bem como os ossos, retalhos e aparas destas porções.

$\mathrm{O}$ rendimento de carcaça quente foi calculado pela relação entre o peso da carcaça quente e o peso 
vivo vazio (PVv), expresso em porcentagem. $\mathrm{O}$ valor do peso vivo vazio foi encontrado pela diferença entre o peso vivo em jejum ( $\mathrm{PVj}$ ) e o peso do conteúdo do trato gastrointestinal. A porcentagem de cortes comerciais foi obtida em relação ao peso da meia carcaça direita resfriada e em relação ao peso das porções que os originaram, como traseiro especial, dianteiro ou ponta de agulha.

As meias carcaças esquerdas serviram para a coleta de amostras do músculo Longissimus dorsi (contra-filé) entre a $9^{\mathrm{a}}$ e a $12^{\mathrm{a}}$ costelas, mensurando-se nesta porção a porcentagem de carne, ossos e retalhos, através de dissecação. Pela secção transversal na altura da $12^{\mathrm{a}}$ costela, avaliou-se a espessura de gordura e a área de olho de lombo. As amostras do contra-filé foram identificadas, acondicionadas em sacos de polietileno e congeladas, para posteriores análises de coloração objetiva, maciez e composição química da carne, realizadas na porção de carne magra retirada da seção entre a $9^{\mathrm{a}}$ e a $12^{\mathrm{a}}$ costelas.

As análises referentes à composição e qualidade da carne foram realizadas no Centro de Tecnologia de Carnes do ITAL. Para as análises da composição química da carne, as amostras foram descongeladas por 24 horas, à temperatura de $7 \mathrm{a} 10^{\circ} \mathrm{C}$ antes de serem analisadas. $\mathrm{O}$ teor de umidade foi determinado utilizando-se a técnica de secagem em estufa. Para a gordura utilizou-se a técnica de extração com éter em aparelhos SOXHLET. O teor de cinzas foi determinado colocando-se o cadinho com a amostra em mufla, mantida a $525^{\circ} \mathrm{C}$, conforme preconizado por HELRICH (1990). O nitrogênio total foi determinado de acordo com a metodologia de KJELDAHL, em aparelho TECATOR.

No tocante à qualidade das carnes, foram realizadas análises para coloração objetiva, utilizando-se aparelho CHROMAMETER DA MINOLTA CR-200b, medindo a luz refletida pela cor, ou seja, iluminação difusa, numa área de $8 \mathrm{~mm}$ de carne. A maciez foi determinada por intermédio da técnica da textura objetiva, pela qual é realizado cozimento em chapa elétrica da amostra embalada em papel alumínio até atingir $72^{\circ} \mathrm{C}$ internamente. Após o cozimento, as amostras atingem a temperatura ambiente ainda embaladas, para em seguida serem cortadas em cilindros de 0,5 polegada e, posteriormente, determinar a força máxima de cisalhamento, em dinamógrafo INSTRON modelo TM-M2315, acoplado com acessórios de WARNER BRATZLER, sendo a velocidade de cisalhamento de $10 \mathrm{~cm} /$ minuto. Os valores de força máxima de cisalhamento foram expressos em kgf.0,5 $\mathrm{pol}^{-1}$.

O delineamento experimental foi o de blocos casualizados (PIMENTEL GOMES, 1985) com 4 tratamentos e 5 repetições, totalizando 20 animais. Os resultados foram analisados através do programa Statistical Analysis System (SAS, 1985), sendo verificada a normalidade dos resíduos pelo Teste de SHAPIRO-WILK e a homogeneidade das variâncias, pelo TESTE F. Estando os dados dentro destas premissas, passaram a ser submetidos à análise de variância através do procedimento GENERAL LINEAR MODELS (PROC GLM), utilizando regressão polinomial para os níveis de resíduos de panificação. Foi adotado um nível de significância de 5\% para todos os testes realizados. Para a análise de variância foi adotado o seguinte modelo matemático:

$$
\mathrm{Y}_{\mathrm{ij}}=\mathrm{M}+\mathrm{T}_{\mathrm{i}}+\mathrm{B}_{\mathrm{j}}+\mathrm{e}_{\mathrm{ij}}
$$

em que: $\mathrm{Y}_{\mathrm{ij}}=$ variáveis estudadas; $\mathrm{M}=$ média geral; $\mathrm{T}_{\mathrm{i}}$ = efeito do tratamento $\mathrm{i}(\mathrm{i}=1-4) ; \mathrm{B}_{\mathrm{j}}=$ efeito do bloco $\mathrm{j}(\mathrm{j}=1-5) ; \mathrm{e}_{\mathrm{ij}}=$ erro aleatório de cada observação.

\section{Resultados e Discussão}

Os valores médios encontrados, bem como os respectivos coeficientes de variação referentes às variáveis analisadas, constam nas Tabelas 4 e 5 .

Não foram encontradas diferenças estatísticas no tocante ao rendimento de carcaça (expresso em porcentagem do peso vivo vazio), cortes do dianteiro resfriado (expresso em porcentagem do peso do dianteiro), cortes do traseiro resfriado (expresso em porcentagem do peso do traseiro), cortes da ponta de agulha (expresso em porcentagem do peso da ponta de agulha), total de cortes comerciais (expressos como porcentagem do peso da $1 / 2$ carcaça resfriada), área de olho de lombo $\left(\mathrm{cm}^{2}\right)$, comprimento e profundidade da carcaça $(\mathrm{cm})$, em função da substituição do milho pelo resíduo de panificação (RP) nos níveis de 10,20 e $30 \%$, sendo os valores médios obtidos de 55,$90 ; 61,60 ; 68,61 ; 66,29 ; 43,98 ; 111,44$; e 33,01 , respectivamente. O mesmo foi observado para luminosidade, umidade, gordura, proteína e minerais, sendo os valores médios obtidos de 41,$45 ; 73,85 ; 0,92$; 24,00 e 1,03, respectivamente.

O PVv foi escolhido para os cálculos em virtude de ser o índice mais preciso do conteúdo de energia e nutrientes contidos no corpo, como descrito por OWENS et al. (1995). O uso do PVv permite computar o 
Tabela 4 - Médias do rendimento de carcaça quente, cortes do dianteiro e traseiro resfriados, total de cortes comerciais, área de olho de lombo, comprimento e profundidade da carcaça

Table 4 - Means of fresh carcass dressing, cold forepart and hinder part cuts, total commercial cuts, loin eye area, length and depth of the carcass

\begin{tabular}{|c|c|c|c|c|c|c|}
\hline \multirow[t]{2}{*}{$\begin{array}{l}\text { Variável } \\
\text { Variable }\end{array}$} & \multicolumn{4}{|c|}{$\begin{array}{l}\text { Tratamento } \\
\text { Treatment }\end{array}$} & \multirow[t]{2}{*}{$\mathrm{CV}$} & \multirow[t]{2}{*}{$\begin{array}{l}\text { Média } \\
\text { Mean }\end{array}$} \\
\hline & $\begin{array}{l}\mathrm{RP} 0 \\
B W 0\end{array}$ & $\begin{array}{l}\mathrm{RP} 10 \\
B W 10\end{array}$ & $\begin{array}{l}\mathrm{RP} 20 \\
B W 20\end{array}$ & $\begin{array}{l}\mathrm{RP} 30 \\
B W 30\end{array}$ & & \\
\hline $\begin{array}{l}\text { Rend. de carcaça quente (\%) } \\
\text { Fresh carcass dressing } \% \text { ) }\end{array}$ & 56,25 & 56,11 & 55,81 & 55,42 & 3,67 & 55,90 \\
\hline $\begin{array}{l}\text { Cortes do dianteiro resfriado (\%) } \\
\text { Cold forepart cuts }(\%)\end{array}$ & 62,00 & 61,98 & 60,68 & 61,73 & 3,09 & 61,60 \\
\hline $\begin{array}{l}\text { Cortes do traseiro resfriado (\%) } \\
\text { Cold hinder part cuts(\%) }\end{array}$ & 68,04 & 68,74 & 68,30 & 69,36 & 3,39 & 68,61 \\
\hline $\begin{array}{l}\text { Cortes da ponta de agulha (\%) } \\
\text { Ribs cuts (\%) }\end{array}$ & 71,88 & 73,29 & 72,52 & 73,85 & 4,73 & 72,89 \\
\hline $\begin{array}{l}\text { Total de cortes comerciais (\%) } \\
\text { Total commercial cuts (\%) }\end{array}$ & 66,28 & 65,92 & 65,64 & 67,31 & 3,86 & 66,29 \\
\hline $\begin{array}{l}\text { Área de olho de lombo }\left(\mathrm{cm}^{2}\right) \\
\text { Loin eve area }\left(\mathrm{cm}^{2}\right)\end{array}$ & 42,70 & 46,69 & 41,92 & 44,63 & 13,36 & 43,98 \\
\hline $\begin{array}{l}\text { Comprimento médio }(\mathrm{cm}) \\
\text { Mean length }(\mathrm{cm})\end{array}$ & 109,00 & 113,18 & 112,65 & 110,91 & 3,84 & 111,44 \\
\hline $\begin{array}{l}\text { Profundidade média }(\mathrm{cm}) \\
\text { Mean depth }(\mathrm{cm})\end{array}$ & 32,60 & 32,85 & 32,73 & 33,85 & 4,35 & 33,01 \\
\hline
\end{tabular}

RP: Resíduo de panificação. Não houve diferença estatística significativa $(P>0,05)$.

$B W$ : Bakery waste. No statistical significant difference $(P>0,05)$.

rendimento de carcaça com maior precisão possível, eliminando-se os erros devidos às variações do conteúdo da digesta presente nos compartimentos do trato gastrointestinal (PICCHI et al., 1979).

Os resultados obtidos no tocante ao peso da carcaça quente e porcentagem de rendimento de carcaça, em relação ao PVv, estão em acordo com os dados obtidos por MILTON e BRANDT (1993), onde a inclusão de 15 ou $30 \%$ de RP em substituição ao milho na dieta de novilhos mestiços, não afetou estes parâmetros $(\mathrm{P}<0,05)$, juntamente com o grau de marmorização. Contudo, no estudo conduzido por MILTON e BRANDT (1993), foi observado um aumento linear nas porcentagens de gordura pélvica, renal e cardíaca $(\mathrm{P}<0,05)$ e na espessura de gordura mensurada na $12^{\mathrm{a}}$ costela $(\mathrm{P}<0,10)$, o que não ocorreu nas condições deste trabalho.

Segundo o Sistema Brasileiro de Classificação e de Tipificação de carcaça, que consta da Portaria $n^{0}$ 07, do MINISTÉRIO DA AGRICULTURA (1978), a gordura de cobertura dos animais no presente estudo foi classificada como ausente $(<1 \mathrm{~mm})$, sendo a musculosidade, baseada na área de olho de lombo, classificada com deficiente $\left(<46 \mathrm{~cm}^{2}\right)$. Estes valores podem ser justificados não só pela precocidade dos animais por ocasião do abate, com cerca de 11 a 12 meses de idade, mas também pela raça utilizada. Tais animais poderiam ser denominados "vitelões". Contudo, esta categoria animal não é dotada de sistemas de classificação e tipificação apropriados, visto que o mercado nacional não é habituado a consumir este tipo de produto, que apresenta, por sua vez, menor porcentagem de gordura na carcaça, maior maciez da carne e, conseqüentemente, preços maiores no mercado.

Como mencionado, além da idade, existem diferenças raciais no tocante à habilidade de deposição de gordura na carcaça, como demonstrado no estudo de BOND et al. (1972). Esses autores afirmaram que novilhos da raça Holandesa ganham peso mais rapidamente e apresentam maior área de olho de lombo $\left(70 \mathrm{~cm}^{2}\right)$ em relação aos animais das raças Jersey, Shorthorn, Angus e Hereford, porém, com pequena cobertura de gordura.

Estas afirmações concordam com os dados obtidos por COLE et al. (1964), os quais relataram que os animais da raça Holandesa apresentam carcaças menos gordurosas, com menor índice de marmorização (gordura entre as fibras musculares) e 
Tabela 5 - Médias da composição química e qualidade da carne dos animais (músculo Longissimus dorsi) Table 5 - Means of chemical composition and meat quality of the animals (Longissimus dorsi muscle)

\begin{tabular}{|c|c|c|c|c|c|c|}
\hline \multirow[t]{2}{*}{$\begin{array}{l}\text { Variável } \\
\text { Variable }\end{array}$} & \multicolumn{4}{|c|}{$\begin{array}{c}\text { Tratamento } \\
\text { Treatment }\end{array}$} & \multirow[t]{2}{*}{$\mathrm{CV}$} & \multirow[t]{2}{*}{$\begin{array}{l}\text { Média } \\
\text { Mean }\end{array}$} \\
\hline & $\begin{array}{l}\mathrm{RP} 0 \\
B W 0\end{array}$ & $\begin{array}{l}\mathrm{RP} 10 \\
B W 10\end{array}$ & $\begin{array}{l}\text { RP } 20 \\
B W 20\end{array}$ & $\begin{array}{l}\text { RP 30 } \\
B W 30\end{array}$ & & \\
\hline \multicolumn{7}{|l|}{ Qualidade da carne } \\
\hline $\begin{array}{l}\text { Meat quality } \\
\text { Luminosidade } \\
\text { Luminosity }\end{array}$ & 41,72 & 40,86 & 40,78 & 42,42 & 10,43 & 41,45 \\
\hline $\begin{array}{l}\text { Maciez }\left(\mathrm{kgf} .0,5 \mathrm{pol}^{-1}\right) \\
\text { Tenderness }\left(\mathrm{kgf.0}, 5 \mathrm{pol}^{-1}\right)\end{array}$ & 2,47 & 2,59 & 2,14 & 3,21 & 28,34 & 2,60 \\
\hline \multicolumn{7}{|l|}{$\begin{array}{l}\text { Composição química }(\%) \\
\text { Chemical composition (\%) }\end{array}$} \\
\hline $\begin{array}{l}\text { Umidade } \\
\text { Moisture }\end{array}$ & 73,62 & 74,57 & 73,59 & 73,63 & 2,39 & 73,85 \\
\hline $\begin{array}{l}\text { Gordura } \\
\text { Fat }\end{array}$ & 0,73 & 0,79 & 1,31 & 0,85 & 59,51 & 0,92 \\
\hline $\begin{array}{l}\text { Proteína } \\
\text { Protein }\end{array}$ & 23,94 & 23,19 & 24,55 & 24,33 & 5,18 & 24,00 \\
\hline $\begin{array}{l}\text { Minerais } \\
\text { Minerals }\end{array}$ & 0,99 & 1,02 & 0,91 & 1,20 & 27,78 & 1,03 \\
\hline
\end{tabular}

RP: Resíduo de panificação. Não houve diferença estatística significativa $(P>0,05)$.

$B W$ : Bakery waste. No statistical significant difference $(P>0,05)$.

com maior percentagem de músculos que os animais de raças zebuínas. OWENS et al. (1995) reforçam estas afirmativas concluindo que animais da raça Holandesa depositam alta proporção de gordura nos órgãos internos (componentes extra-carcaça) em relação à carcaça propriamente dita, diferentemente das raças de corte tradicionais.

MILTON e BRANDT (1993) sugeriram que o uso de elevadas quantidades de RP, para novilhos em confinamento, poderia modificar as características da carcaça, principalmente a deposição de gordura. Entretanto, no presente estudo, nenhuma diferença foi observada na espessura de gordura dos animais nos diferentes tratamentos $(\mathrm{P}>0,05)$, fato que pode ser atribuído à raça utilizada, bem como à precocidade da idade ao abate.

Não existem, nas literaturas nacional e internacional, outros relatos de estudos sobre os efeitos do uso do RP nas características de carcaça de bovinos, contudo, tomando a afirmativa de MATTOS et al. (1978) como verdadeira, os quais afirmaram que as exigências de mercado evoluem no sentido da preferência para a carne magra, os animais da raça Holandesa merecem destaque, por apresentarem porcentagens mínimas de gordura na carcaça.

\section{Conclusões}

O resíduo de panificação adicionado à ração de bovinos até a proporção de $30 \%$ em substituição ao milho não alterou o rendimento de carcaça, a porcentagem de cortes comerciais totais da carcaça, a composição química e a qualidade da carne dos animais. O resíduo de panificação pode ser usado como fonte alternativa para alimentação de bovinos, reduzindo os custos de produção.

\section{Agradecimento}

Ao Prof. Dr. Rodolfo Cláudio Spers, pela disponbilização do resíduo de panificação usado neste trabalho; ao Prof. Dr. Paulo Henrique Mazza Rodrigues, pela orientação com as análises estatísticas; ao Prof. Dr. Evaldo Antonio Lencioni Titto, por auxiliar na revisão deste artigo; à FAPESP, pelo auxílio à pesquisa e pela bolsa de estudo concendidos; e à Dra. Eunice Yamada, do Centro de Tecnologia de Carnes (CTC), Instituto de Tecnologia de Alimentos (ITAL), pela análise qualitativa das carnes deste estudo. 


\section{Referências Bibliográficas}

ADAMS, R.S. Use of commodity ingredients and food processing wastes in the northeast. In: DAIRY FEEDING SISTEMS SYMPOSIUM, 1990, Harrisburg. Proceedings... Pennsylvania, USA, 1990. p.176-183.

ASSOCIATION OF OFFICIAL ANALYTICAL CHEMISTS AOAC. 1985. Official methods of analysis of the OAC international. 13.ed. Washington, D.C. 1095p.

AROSEMENA, A., DePETERS, E.J., FADEL, J.G. 1995. Extent of variability in nutrient composition within selected byprodutc feedstuffs. Anim. Feed Sci. and Techn., 54:103-120.

BATH, D., DUNBAR, J., KING, J. et al. 1993/94. Byproducts and unusual feedstuffs. Feedstuffs, 61(31):32-37.

BEAUCHEMIN, K.A., LACHANCE, B., St.LAURENT, G. 1990. Effects of concentrate diets on performance and carcass characteristics of veal calves. J. Anim. Sci., 68:35-44.

BOND, J., HOOVEN JR., N.N., WARICH, E.S. et al. 1972. Influence of breed and plane of nutrition on performance of dairy, dual-purpose and beef steers. II-From 180 days of age to slaughter. J. Anim. Sci., 34(6):1046-1053.

CHAMPE, K.A., CHURCH, D.C. 1980. Digestibility of dried bakery product by sheep. J. Anim. Sci., 51(1):25-27.

COLE, J.W., RAMSEY, C.B., HOBBS, C.S. et al. 1964. Effects of type and breed of British, Zebu and dairy cattle on production, palatability and composition. III-Percent wholesale cuts and yield of edible portion as determined by physical and chemical analysis. J. Anim. Sci., 23(1):71-77.

DALE, N.M. 1986. Energy and nutrient content of dried bakery product and crab meal. Poult. Sci., 65:163. (suplemento1).

HARMS, R.H., DAMRON, B.L., WALDROUP, P.W. 1966. Dried bakery product as an ingredient for poultry feeds. Feedstuffs, 38(42):42-43.

HARRIS JR., B., STAPLER, C.R. 1993. Feeding by-product feedstuffs to dairy cattle. Gainesville: University of Florida, Dairy Science Department. p.1-6.

HELRICH, K. 1990. Official methods of analysis. 15.ed. Arlington: Association of Official Analytical Chemists. 1298p.

KORNEGAY, E.T. 1974. Blended dried bakery product for growing and finishing swine. Feedstuffs, 46(15):23.

LUCCI, C.S. 1989. Bovinos leiteiros jovens: nutrição, manejo, doenças. 1.ed. São Paulo: Nobel/EDUSP. 371p.

MATTOS, J.C.A., PACOLA, L.J., LIMA, F.P. et al. 1978. Estudo comparativo entre carcaças de novilhos da raça Nelore e de novilhos mestiços. Bol. Ind. Anim., 35(1):25-31.

MILLER, E.R., HOLDEN, P.J., LEIBBRANDT, V.D.(s.d.) Byproducts in swine diets. Pork Industry Handbook, Purdue University Cooperative Extension Service, PIH-108.

MILTON, C.T., BRANDT, R.T. 1993. Utilization of dried bakery product by finishing beef steers. Cattlemen's Day, p.104-106.
MINISTÉRIO DA AGRICULTURA. 1978. Secretaria Nacional de Produção Agropecuária. Portaria n ${ }^{\circ} 07$, de 26 de setembro de 1978. Diário Oficial, Brasília, p.15929-15933.

MORRISON, F.B. 1966. Alimentos e alimentação dos animais. 2.ed. São Paulo: Edições Melhoramentos. 892p.

NATIONAL RESEARCH COUNCIL - NRC. 1989. Nutrient requirements of dairy cattle. Washington, D.C.: National Academy Press. $157 \mathrm{p}$.

OLIVEIRA, J.B., PRADO, W. 1984. Levantamento pedológico do Estado de São Paulo: quadrículo de São Carlos. Boletim Técnico-Instituto Agronômico. Campinas, Instituto Agronômico. 38p.

OWENS, F.N., GILL, D.R., SECRIST, D.S. et al. 1995. Review of some aspects of growth and development of feedlot cattle. J. Anim. Sci., 73:3152-3172.

PICCHI, V., FELÍCIO, P.E., CIA, G. 1979. Sistematização da avaliação final de bovinos e bubalinos.I.Composição corporal. Bol. Téc. do Centro de Tecnologia da Carne, Campinas. 53p.

PIMENTEL GOMES, F. 1985. Curso de estatística experimental. Piracicaba: ESALQ.

Statistical Analysis System. 1985. 5.ed. Cary, NC, SAS Institute. SPERS, R.C. Efeito da substituição do milho e do farelo de soja pelo resíduo de panificação no desempenho de bubalinos em crescimento. Botucatu, SP:UNESP, 1996. 27p. Dissertação (Mestrado em Zootecnia) - Faculdade de Medicina Veterinária e Zootecnia/Universidade Estadual Paulista,1996.

VELLOSO, L., SILVA, L.R.M., BOIN, C. et al. 1975. Desenvolvimento de bovinos mestiços holandeses inteiros e castrados, em regime de confinamento e as características das carcaças. Bol. Ind. Anim., 32(1):37-45.

WING, J.M. 1965. Preliminary evaluation of dried bakery product in dairy cattle rations. Feedstuffs, 37(19):38 e 128.

ZEMBAYASHI, M. 1994. Effects of nutritional planes and breeds on intramuscular-lipid deposition in M. longissimus dorsi of steers. Meat Sci., 38:367-374.

Recebido em: 07/07/00 Aceito em: 14/05/01 